\title{
The value of septal rebound stretch analysis for the prediction of volumetric response to cardiac resynchronization therapy
}

\author{
Citation for published version (APA):
}

Salden, O. A. E., Zweerink, A., Wouters, P., Allaart, C. P., Geelhoed, B., de Lange, F. J., Maass, A. H., Rienstra, M., Vernooy, K., Vos, M. A., Meine, M., Prinzen, F. W., \& Cramer, M. J. (2021). The value of septal rebound stretch analysis for the prediction of volumetric response to cardiac resynchronization therapy. European Heart Journal Cardiovascular Imaging, 22(1), 37-45.

https://doi.org/10.1093/ehjci/jeaa190

Document status and date:

Published: 01/01/2021

DOI:

10.1093/ehjci/jeaa190

Document Version:

Publisher's PDF, also known as Version of record

\section{Document license:}

Taverne

Please check the document version of this publication:

- A submitted manuscript is the version of the article upon submission and before peer-review. There can be important differences between the submitted version and the official published version of record.

People interested in the research are advised to contact the author for the final version of the publication, or visit the DOI to the publisher's website.

- The final author version and the galley proof are versions of the publication after peer review.

- The final published version features the final layout of the paper including the volume, issue and page numbers.

Link to publication

\footnotetext{
General rights rights.

- You may freely distribute the URL identifying the publication in the public portal. please follow below link for the End User Agreement:

www.umlib.nl/taverne-license

Take down policy

If you believe that this document breaches copyright please contact us at:

repository@maastrichtuniversity.nl

providing details and we will investigate your claim.
}

Copyright and moral rights for the publications made accessible in the public portal are retained by the authors and/or other copyright owners and it is a condition of accessing publications that users recognise and abide by the legal requirements associated with these

- Users may download and print one copy of any publication from the public portal for the purpose of private study or research.

- You may not further distribute the material or use it for any profit-making activity or commercial gain

If the publication is distributed under the terms of Article $25 \mathrm{fa}$ of the Dutch Copyright Act, indicated by the "Taverne" license above, 


\title{
The value of septal rebound stretch analysis for the prediction of volumetric response to cardiac resynchronization therapy
}

\author{
Odette A.E. Salden ${ }^{1}{ }^{1} *$, Alwin Zweerink ${ }^{2}$, Philippe Wouters ${ }^{1}$, Cornelis P. Allaart ${ }^{2}$, \\ Bastiaan Geelhoed $^{3}$, Frederik J. de Lange ${ }^{2}$, Alexander H. Maass ${ }^{2}$, \\ Michiel Rienstra $\mathbb{1}^{3}{ }^{3}$, Kevin Vernooy ${ }^{4,5}$, Marc A. Vos ${ }^{6}$, Mathias Meine ${ }^{1}$, \\ Frits W. Prinzen ${ }^{5}$, and Maarten J. Cramer ${ }^{1}$
}

${ }^{1}$ Department of Cardiology, University Medical Center Utrecht, Heidelberglaan 100, 3584 CX Utrecht, the Netherlands; ${ }^{2}$ Department of Cardiology, Amsterdam University Medical Center, Meibergdreef 9, 1105 AZ Amsterdam, the Netherlands; ${ }^{3}$ Department of Cardiology, University Medical Center Groningen, Hanzeplein 1, 9713 GZ Groningen, the Netherlands; ${ }^{4}$ Department of Cardiology, Maastricht University Medical Center, P. Debyelaan 25, 6229 HX Maastricht, the Netherlands; ${ }^{5}$ Department of Physiology, Cardiovascular Research Institute Maastricht (CARIM), Maastricht University, Universiteitssingel 50, 6229 ER Maastricht, the Netherlands; and ${ }^{6}$ Department of Medical Physiology, University of Utrecht, Yalelaan 50, 3584 CM Utrecht, the Netherlands

Received 6 February 2020; editorial decision 19 May 2020; accepted 2 June 2020; online publish-ahead-of-print 23 July 2020

Aims

Patient selection for cardiac resynchronization therapy (CRT) may be enhanced by evaluation of systolic myocardial stretching. We evaluate whether systolic septal rebound stretch (SRSsept) derived from speckle tracking echocardiography is a predictor of reverse remodelling after CRT and whether it holds additive predictive value over the simpler visual dyssynchrony assessment by apical rocking (ApRock).

Methods The association between SRSsept and change in left ventricular end-systolic volume ( $\Delta$ LVESV) at 6 months of and results follow-up was assessed in 200 patients. Subsequently, the additive predictive value of SRSsept over the assessment of ApRock was evaluated in patients with and without left bundle branch block (LBBB) according to strict criteria. SRSsept was independently associated with $\triangle \operatorname{LVESV}(\beta$ 0.221, $P=0.002)$ after correction for sex, age, ischaemic cardiomyopathy, QRS morphology and duration, and ApRock. A high SRSsept ( $\geq$ optimal cut-off value 2.4) also coincided with more volumetric responders ( $\triangle \mathrm{LVESV} \geq-15 \%)$ than low SRSsept in the entire cohort $(70.0 \%$ and $56.4 \%$ ), in patients with strict LBBB (83.3\% vs. 56.7\%, $P=0.024)$, and non-LBBB $(70.7 \%$ vs. $46.3 \%, P=0.004)$. Moreover, in non-LBBB patients, SRSsept held additional predictive information over the assessment of ApRock alone since patients that showed ApRock and high SRSsept were more often volumetric responder than those with ApRock but low SRSsept ( $82.8 \%$ vs. $47.4 \%, P=0.001)$.

Conclusion $\quad$ SRSsept is strongly associated with CRT-induced reduction in left ventricular end-systolic volume and holds additive prognostic information over QRS morphology and ApRock. Our data suggest that CRT patient selection may be improved by assessment of SRSsept, especially in the important subgroup without strict LBBB.

Clinical trial The MARC study was registered at clinicaltrials.gov: NCT01519908.

registration

Keywords

cardiac resynchronization therapy $\bullet$ left bundle branch block • dyssynchrony $\bullet$ echocardiography $\bullet$ strain

*Corresponding author. Tel: +31 8875535 06. E-mail: o.a.e.salden@umcutrecht.nl

Published on behalf of the European Society of Cardiology. All rights reserved. @ The Author(s) 2020. For permissions, please email: journals.permissions@oup.com. 


\section{Introduction}

Cardiac resynchronization therapy (CRT) is an effective treatment for patients with advanced systolic heart failure and a prolonged QRS duration. In current CRT guideline recommendations, patient selection is primarily guided by QRS morphology and duration. ${ }^{1,2}$ Yet, due to an overall reported non-responders rate of $30-40 \%$, there is room for improvement of patient selection. ${ }^{3}$ Whether echocardiographic dyssynchrony parameters can enhance the selection of patients has been an area of debate since the multicentre PROSPECT trial was not able to show additive benefit of the use of (timing-based) echocardiographic dyssynchrony markers for predicting CRT outcomes. ${ }^{4}$ In the meantime, the field of echocardiography has moved from using timing-based dyssynchrony measures towards the detection of specific wall motion patterns to serve as markers for CRT response. ${ }^{5-8}$ These specific wall motion patterns can be identified by the visual assessment of dyssynchrony and quantified by myocardial strain imaging techniques. ${ }^{5,9-11}$ A pre-ejection, short septal contraction pulling the apex septally followed by a delayed lateral wall contraction, which causes a lateral motion of the apex-known as apical rocking (ApRock) - is a specific pattern of contraction that has been shown to be strongly associated with better survival and volumetric CRT response. ${ }^{12-15}$ Still, when using ApRock to determine the presence of dyssynchrony, a continuous mechanical process is translated to a binary yes/no phenomenon. Speckle tracking echocardiography, on the other hand, allows for a detailed quantification of left ventricular (LV) dyssynchrony often called discoordination. Previous work revealed that the interplay between early septal contraction and delayed lateral wall activation results in myocardial stretching of the opposing wall during systole. , $8,16,17$ This paradoxical systolic LV stretching does not contribute to LV ejection and, hence, causes a waste of energy. Biventricular pacing may convert systolic stretching into shortening and, therefore, may, reduce myocardial wasted work. ${ }^{5,18,19}$ Previous work suggested that the amount of systolic stretching of the septum after initial systolic shortening ['systolic rebound stretch of the septum'(SRSsept)] reflects the potential for recovery of LV function with CRT, and may be used to identify potential CRT responders., 50,21 Yet, this parameter has not been validated in a multicentre setting. Therefore, the primary objective of the present study was to investigate whether SRSsept is a robust predictor of LV reverse remodelling defined as reduction in LV endsystolic volume ( $\triangle$ LVESV) in a multicentre setting. ${ }^{14}$ The secondary objective was to test the additive prognostic power of SRSsept when evaluated in addition to the simpler visual assessment of dyssynchrony by ApRock for the prediction of volumetric response after CRT ( $\triangle \mathrm{LVESV} \geq 15 \%$ ). Lastly, we assessed the value of mechanical dyssynchrony in patients with and without strict left bundle branch block (LBBB).

\section{Methods}

\section{Patient population}

This is a subanalysis of the prospective multicentre Markers of Response to Cardiac Resynchronization Therapy (MARC) study. ${ }^{14}$ The MARC study included 240 patients with a CRT device with defibrillator function and was designed to investigate which clinical, electrical, and echocardiographic parameters can improve CRT response prediction. All electrocardiograms (ECGs) were assessed by a blinded ECG core lab (University Medical Center of Utrecht), and all echocardiograms were handled by a blinded echocardiography core lab (University Medical Center of Utrecht). The study was initiated and co-ordinated by the six centres within the framework of the Center for Translational Molecular Medicine (CTMM), project COHFAR. Details of the original MARC study were published previously. ${ }^{14}$ In short, inclusion criteria were sinus rhythm, LBBB with QRS duration $\geq 130 \mathrm{~ms}$ or $\geq 150 \mathrm{~ms}$ in non-specific interventricular conduction delay (IVCD) for patients with New York Heart Association (NYHA) Class II, LBBB with QRS duration $\geq 120 \mathrm{~ms}$, or QRS duration $\geq 150$ ms in non-specific IVCD patients with NYHA Class III. Exclusion criteria were severe renal insufficiency $(<30 \mathrm{~mL} / \mathrm{min} /$ $1.73 \mathrm{~m}^{2}$ ), previous pacemaker implantation, right bundle branch block, and permanent atrial fibrillation. Of the 240 patients included in the MARC study 213 patients had pre- and post-implant echocardiography data with paired LV end-systolic volume (LVESV) measurements available (two failed implants, five implants not attempted, four deaths, four withdrawn consents, one missed visit, and eleven unperformed of unreadable echocardiogram studies). The study was performed according to the Declaration of Helsinki. All patients provided written informed consent and all local medical ethics committees approved data collection and management. Of note, the data underlying this article is managed by the Universtity Medical Center of Groningen (MARC statistical core lab). Data may be shared on reasonable request to the corresponding author with permission of the University Medical Center of Groningen.

\section{Echocardiographic analysis}

Echocardiograms of baseline and 6 months of follow-up after CRT implantation were digitally stored and sent to the echocardiography core lab for detailed analysis, which has been described in detail before. ${ }^{14}$ Standard echocardiographic images were obtained, accompanied with a zoomed and trimmed image of the left ventricle and the interventricular septum, in apical four-chamber view. Frame rate of images obtained for speckle tracking echocardiography was optimized to range between 50 and $120 \mathrm{~Hz}$. All echocardiograms were analysed with a dedicated vendorindependent software platform (TomTec Cardiac Performance Analysis, TomTec Imaging Systems GmbH, Unterschleissheim, Germany). The LV end-diastolic volume and end-systolic volume and ejection fraction were measured on three separate beats, using the biplane Simpson's method. Volumetric response to CRT was determined as a $\geq 15 \%$ decrease in LVESV between baseline and 6 months of follow-up. Systole was defined by the onset of the QRS complex and aortic valve closure time obtained from pulsed-wave Doppler of the LV outflow tract.

\section{Mechanical dyssynchrony parameters}

ApRock was prospectively assessed on baseline conventional echocardiographic views as described before. ${ }^{14}$ ApRock was defined as a short systolic rocking motion of the apex, observed in the apical four-chamber view. ${ }^{9,22}$ SRSsept was defined as the total amount of systolic stretch after initial shortening of the septum ${ }^{5}$ (Figure 1). The amount of SRSsept was obtained by analysis of septal longitudinal strain, which was performed by an observer blinded for volumetric response. The region of interest was set along the endocardial border from base to apex, excluding the apical cap, and adapted to match the wall thickness. The quality of speckle tracking performed by the software was visually checked and adjusted if necessary. SRSsept was determined on septal single wall echocardiographic views when possible (in $61 \%$ of patients) or when a septal single wall view was missing on zoomed four-chamber view (39\% of patients). Images were deemed 'not analysable' if tracking of more than one segment per 

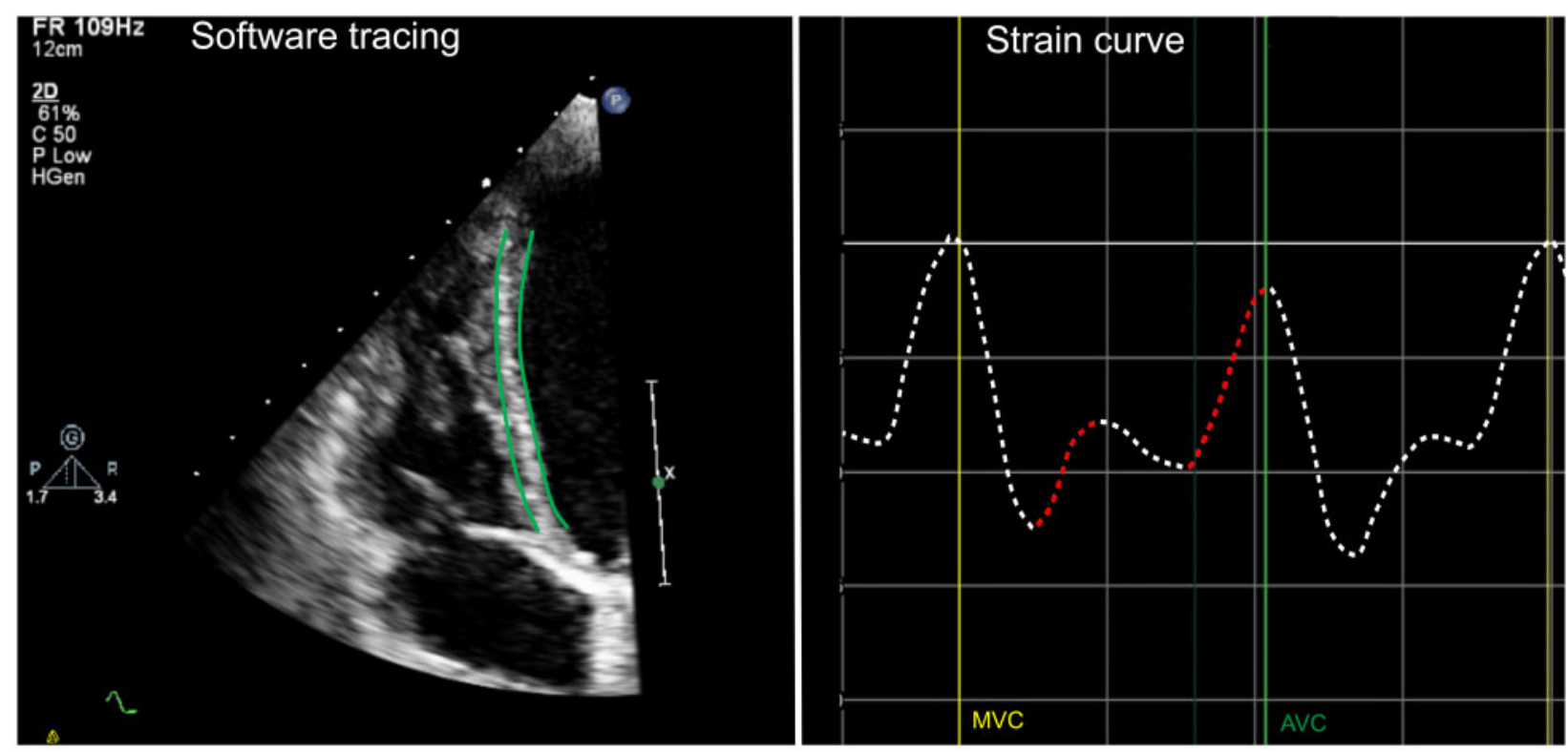

Figure I Acquisition of systolic rebound stretch of the septum on septal single wall image. Strain curves of the focused LV septal wall image derived with dedicated speckle tracking echocardiography software. SRSsept (in red) is defined as septal stretching after initial shortening. The apical cap is excluded from speckle tracking analysis. AVC, aortic valve closing; MVC, mitral valve closing.

\section{Table I American criteria to define left bundle branch block}

\begin{tabular}{ll}
\hline AHA/ACC/HRS & - \\
& - NRS $\geq 120$ \\
& - Octch-, slurred R in I, aVL, V5, and V6 \\
- Absent q in I, V5-V6, and aVL & Absent \\
- R peak time > 60 ms in V5 and V6 \\
- Normal R-peak time in V1-V3 \\
- No negative concordance \\
- Usually discordant ST-T segments
\end{tabular}

wall was not feasible. Images with frame rate between 50 and $120 \mathrm{~Hz}$ were amenable for analysis.

\section{Electrocardiography}

A 12-lead ECG's were recorded at baseline and analysed by the ECG core lab. The presence of LBBB was determined retrospectively by one experienced reader based on morphological features. This was done for the more strict American Heart Association/American College of Cardiology/Heart Rhythm Society (AHA/ACC/HRS) definition for LBBB (Table 1). ${ }^{23}$ In order to qualify as LBBB, an ECG had to comply with all the required criteria for that definition. Patients who did not comply with the LBBB definition were labelled as non-LBBB. QRS duration was determined by the automated ECG algorithm.

\section{Statistical analysis}

Statistical tests were performed in SPSS version 25 (IBM, Armonk, NY, USA). Continuous data were expressed using mean \pm standard deviation (normally distributed variables) or as median, interquartile range (non-normally distributed variables). Categorical data were described by an absolute number of occurrences and associated frequency (\%). Data of subgroups were compared using a $t$-test or Mann-Whitney $U$ test, dependent on normality of the data. Fisher's $\chi^{2}$ test was used for categorical data. The c-statistic and cut-off value of SRSsept were calculated with volumetric response as a dichotomous parameter. Furthermore, intra-observer variability of SRSsept was determined by comparing the first and second analysis (interval of 12 weeks) of the observer, for which interclass correlation coefficient (ICC) were reported. To test the association between baseline SRSsept and reverse remodelling at follow-up, univariable and multivariable adjusted linear regression analyses were performed with correction for potential confounders. Confounders were selected based on baseline differences between patients with high and low SRSsept, and parameters that showed an association with $\triangle$ LVESV in univariable analysis with $P<0.1$. Variables that were added to the final model were: sex, age, ischaemic cardiomyopathy, LBBB morphology, QRS duration, ApRock, and high SRSsept. Assumptions of multivariable linear regression were checked for the existence of non-linearity, heteroskedasticity, and multicollinearity by graphical analyses and correlations tests. Normality of residuals was tested by a Q-Q plot. Furthermore, because visual dyssynchrony assessment by ApRock can be assessed relatively easily on standard 2D echocardiography, the additive prognostic power of the-relatively difficult-SRSsept over ApRock was evaluated. This was done for (i) the total study population and (ii) separately for patients with and without a strict LBBB. Finally, at 6 months of follow-up differences in $\triangle$ LVESV were compared for patients who kept their mechanical dyssynchrony and patients in whom mechanical dyssynchrony was corrected, for which a cut-off was arbitrarily chosen at $50 \%$ change in SRSsept. A two-sided $P$-value of $<0.05$ was considered significant. 


\section{Results}

Of the 213 patients with paired LVESV measurements, a total of seven patients had missing strain data due to irregular heart rhythm $(n=1)$, a frame rate below $35 \mathrm{~Hz}(n=3)$, or an overall low image quality $(n=3)$. Furthermore, six patients had missing baseline ECGs. As a result, 200 patients were included representing a typical CRT cohort, predominantly men (62\%) with a mean age of $67 \pm 10$ years, reduced ejection fraction of $26 \pm 7 \%, 42 \%$ with an ischaemic cardiomyopathy, and $30 \%$ with an LBBB and QRS duration of $179 \pm 23 \mathrm{~ms}$ (Table 2). Median SRSsept was 2.0\% (interquartile range $0.7-4.5$ ) and the overall intra-observer agreement for SRSsept was high [ICC 0.89 (0.69-0.88), $P<0.001]$. A c-statistic of $0.65(0.58-0.72), P<0.001$ was found with a best-fit cut-off value of $2.4 \%$ SRSsept (sensitivity of $0.541 \%$, specificity of $0.728 \%$ ). The c-statistics of SRSsept derived from the septal single wall $(0.69, P<0.001)$ and the apical fourchamber image $(0.60, P=0.08)$ are displayed in Supplementary data online, Figure S1.

\section{Mechanical dyssynchrony and volumetric CRT response}

The baseline characteristics for patients with high $(\geq 2.4 \%)$ and low $(<2.4 \%)$ SRSsept are displayed in Table 2. Based on significant baseline differences, eight variables were identified as possible confounders in the association between baseline SRSsept and reverse remodelling at follow-up being sex, age, origin of heart failure, renal dysfunction, LBBB morphology, QRS duration, and ApRock. After correction for univariable predictors of $\triangle \mathrm{LVESV}$ with a multivariable linear regression model, SRSsept was significantly associated with $\Delta$ LVESV $(\beta$
0.221, $P=0.002$ ) (Table 3). In Supplementary data online, Table S1, similar results are displayed for the association between SRSsept and $\Delta \operatorname{LVEF}(\beta 0.181, P=0.017)$.

\section{Additive prognostic value of septal rebound stretch to visual dyssynchrony assessment by apical rocking}

When assessing volumetric response to CRT, 121 patients (60.5\%) showed volumetric response at 6 months of follow-up with a mean $\Delta$ LVESV of $-21.8 \pm 24.1 \%$. Patients with high SRSsept more often were volumetric responder than patients with low SRSsept $(75.0 \%$ vs. 49.1\%, $P<0.001)$. Furthermore, because ApRock can be assessed relatively easily on standard $2 \mathrm{D}$ echocardiography, the additive prognostic power of the - relatively difficult-SRSsept over ApRock was evaluated and displayed in Figure 2. Similarly to patients with high SRSsept, patients with ApRock showed more response to CRT compared to patient that did not display ApRock (71.1\% vs. $41.7 \%$, $P<0.001)$. Still, of all the patients that showed ApRock, $43 \%$ displayed low SRSsept $(n=55)$. In these patients, the response rate was only $54.5 \%$, while patients with both ApRock and a high SRSsept $(n=73)$ had the highest response rate of $83 . \%(P<0.001)$.(Figure 2$)$ Of note, in patients that did not show ApRock $(n=72)$, response rates were similar between patients with high $(n=15)$ or low $(n=55)$ SRSsept (33.3\% vs. $43.9 \%, P=0.462$, respectively). In Figure 3, four representative septal strain curves are displayed for patients with or without ApRock and high or low SRSsept.

\section{Table 2 Baseline characteristics}

\begin{tabular}{|c|c|c|c|c|}
\hline & All patients & SRSsept $\geq 2.4 \%(n=88)$ & SRSsept $<2.4 \%(n=112)$ & $P$-value \\
\hline \multicolumn{5}{|l|}{ Demographics } \\
\hline Male sex, n (\%) & $124(62.0)$ & $42(47.7)$ & $82(73.2)$ & $<0.001$ \\
\hline Age (years) & $67 \pm 10$ & $66 \pm 10$ & $68 \pm 9$ & 0.054 \\
\hline \multicolumn{5}{|l|}{ NYHA functional class, $n$ (\%) } \\
\hline Class II/IV & $125(62.5)$ & $54(61.4)$ & $70(62.5)$ & \\
\hline Class III/IV & $75(37.5)$ & $34(38.6)$ & $41(36.6)$ & 0.654 \\
\hline Ischaemic cardiomyopathy, n (\%) & $84(42.0)$ & $29(33.0)$ & $55(49.1)$ & 0.022 \\
\hline History of atrial fibrillation, $n$ (\%) & $25(12.5)$ & $9(10.2)$ & $16(14.3)$ & 0.389 \\
\hline Diabetes, $n(\%)$ & $51(25.5)$ & $19(21.6)$ & $32(28.6)$ & 0.261 \\
\hline Kidney dysfunction, $n$ (\%) & $9(4.5)$ & $8(9.1)$ & $1(0.9)$ & 0.006 \\
\hline \multicolumn{5}{|l|}{ Echocardiography } \\
\hline LV ejection fraction (\%) & $25.8 \pm 7.4$ & $25.8 \pm 6.8$ & $25.7 \pm 8.2$ & 0.936 \\
\hline LV ESV (mL) & $133(96-182)$ & $132(99-179)$ & $134(92-186)$ & 0.416 \\
\hline LV EDV (mL) & $178(145-234)$ & $179(146-237)$ & $178(137-232)$ & 0.465 \\
\hline \multicolumn{5}{|l|}{ Electrocardiography } \\
\hline LBBB, $n(\%)$ & $60(30.0)$ & $30(34.1)$ & $30(26.8)$ & 0.263 \\
\hline QRS duration (ms) & $179 \pm 23$ & $182 \pm 25$ & $174 \pm 21$ & 0.023 \\
\hline PR interval (ms) & $185(168-212)$ & $184(167-205)$ & $187(168-240)$ & 0.220 \\
\hline \multicolumn{5}{|l|}{ Plain dyssynchrony } \\
\hline Apical rocking, n (\%) & $128(64.0)$ & $73(83.0)$ & $55(49.1)$ & $<0.001$ \\
\hline
\end{tabular}

EDV, end-diastolic volume; ESV, end-systolic volume; LBBB, left bundle branch block; LV, left ventricular. 
Table 3 Univariable and multivariable analysis of association with change in LVESV

\begin{tabular}{|c|c|c|c|c|}
\hline & \multicolumn{2}{|l|}{ Univariable } & \multicolumn{2}{|l|}{ Multivariable } \\
\hline & $\beta$ (standardized) & $P$-value & $\beta$ (standardized) & $P$-value \\
\hline Female sex, $n(\%)$ & 0.180 & 0.011 & -0.018 & 0.790 \\
\hline Age (years) & -0.190 & 0.007 & -0.121 & 0.069 \\
\hline Ischaemic cardiomyopathy, $n$ (\%) & -0.319 & $<0.001$ & -0.182 & 0.013 \\
\hline Kidney dysfunction, $n(\%)$ & -0.052 & 0.468 & & \\
\hline LBBB morphology, n (\%) & 0.215 & 0.002 & 0.150 & 0.022 \\
\hline QRS duration (ms) & 0.155 & 0.030 & 0.050 & 0.459 \\
\hline Apical rocking, n (\%) & 0.324 & $<0.001$ & 0.149 & 0.041 \\
\hline SRSsept (\%) & 0.354 & $<0.001$ & 0.221 & 0.002 \\
\hline
\end{tabular}

$\beta$, standardized regression coefficient (represents the number of standard deviations that the outcome will change as a result of one standard deviation change in the predictor); LBBB, left bundle branch block; SRSsept, systolic rebound stretch of the septum.

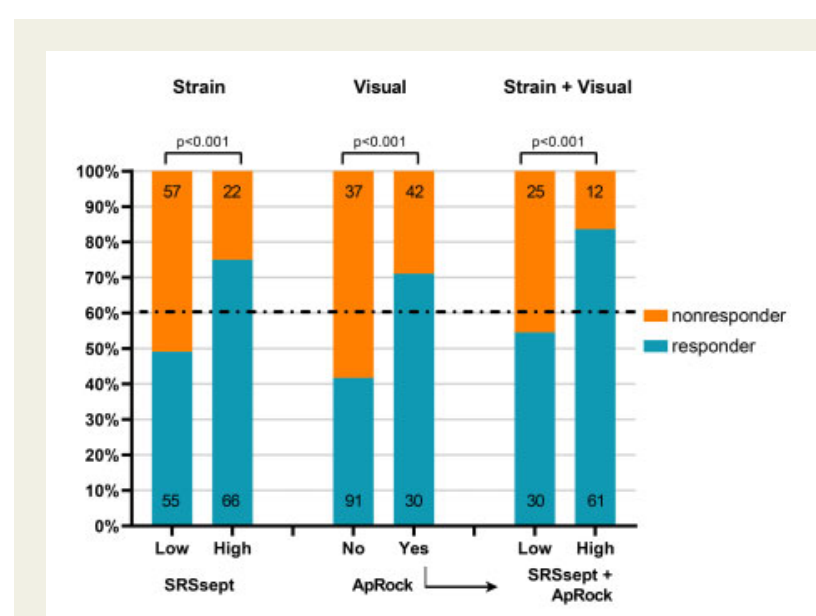

Figure 2 Discriminative ability of SRSsept for the prediction of volumetric CRT response. The percentage of responders (blue) and non-responders (orange) are displayed for patients with high vs. low SRSsept (left), patients with and without apical rocking (middle), and patients with apical rocking and high or low SRSsept (right). Dotted line represents overall response to CRT in the study population. Numbers represent total amount of patients. ApRock, apical rocking; AVC, aortic valve closing; MVC, mitral valve closing; SRSsept, systolic rebound stretch of the septum.

\section{Mechanical dyssynchrony in patients with a strict LBBB}

Overall response in patients with a strict LBBB $(n=60)$ was $70 \%$. High SRSsept values were observed in $50 \%$ of patients, whereas ApRock was observed in $77 \%$ of patients. LBBB patients with either high SRSsept or ApRock displayed more volumetric response compared to patients with low SRSsept or without ApRock (SRSsept: 83.3\% vs. 56.7\%, $P=0.024$ and ApRock 78.3\% vs. $42.9, P=0.011$ ). When SRSsept was evaluated on top of ApRock, there was a nonsignificant trend towards more responders in patients with ApRock and high SRSsept compared to patients with ApRock but low SRSsept (82.8\% vs. $70.6 \%, P=0.334$ ) (Figure 4 ).

\section{Mechanical dyssynchrony in patients without a strict LBBB}

In patients without strict LBBB $(n=140)$ only $56.4 \%$ displayed volumetric response. In total, $41.4 \%$ of non-LBBB patients had high SRSsept values, 58.6\% displayed ApRock, and 31.4\% displayed both ApRock and high SRSsept. Assessment of SRSsept led to a better discrimination between responders and non-responders, since response rates were higher among patients with high SRSsept compared to patients with low SRSsept (70.7\% vs. $46.3 \%, P=0.004)$. Moreover, assessment of SRSsept held additional predictive value over assessment of ApRock alone, given that patients that displayed both ApRock and high SRSsept more frequently were responder compared to patients with ApRock and low (84.1\% vs. $47.4 \%, P=0.001)$ (Figure 4).

\section{Correction of mechanical dyssynchrony at follow-up}

Six months after CRT implantation, larger $\triangle$ LVESV was observed in patients that displayed a $\geq 50 \%$ reduction in SRSsept $(n=60)$ compared to patients with $a<50 \%$ reduction $(n=140) \quad(\Delta L V E S V$ : $-26 \pm 23 \%$ vs. $-13 \pm 24 \%, P=0.001)$. Larger reductions in SRSsept tended to result in more reverse remodelling in both subgroup of patients with either baseline low SRSsept ( $\triangle$ LVESV $-19 \pm 22 \%$ vs. $-10 \pm 23 \%, P=0.052$ ), and baseline high SRSsept ( $\triangle$ LVESV: $-32 \pm 26 \%$ vs. $-23 \pm 25 \%, P=0.201)$, yet, in these subgroups differences did not reach statistical significance.

\section{Discussion}

This is the first multicentre study that investigated the association of baseline echocardiographic SRSsept with volumetric response after CRT. Our main findings were (i) SRSsept is independently associated with favourable changes in LVESV after CRT, (ii) assessment of SRSsept holds additional predictive information over the assessment of the more simple visual assessment of ApRock alone for the prediction of volumetric response, and (iii) particularly in patients without a strict LBBB, in whom response to CRT is less certain, SRSsept is able to identify patients who benefit more favourably from CRT. 
A Responder with both apical rocking and high SRSsept

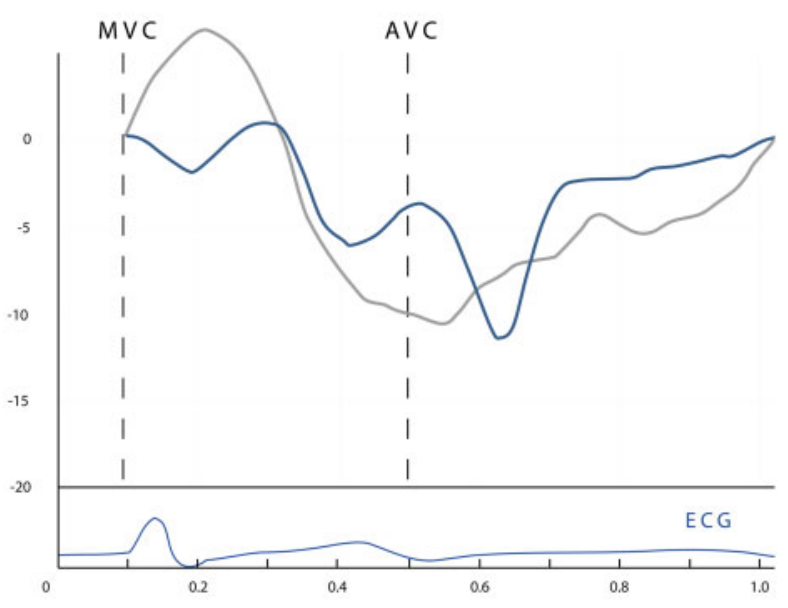

C Non-responder with apical rocking but low SRSsept

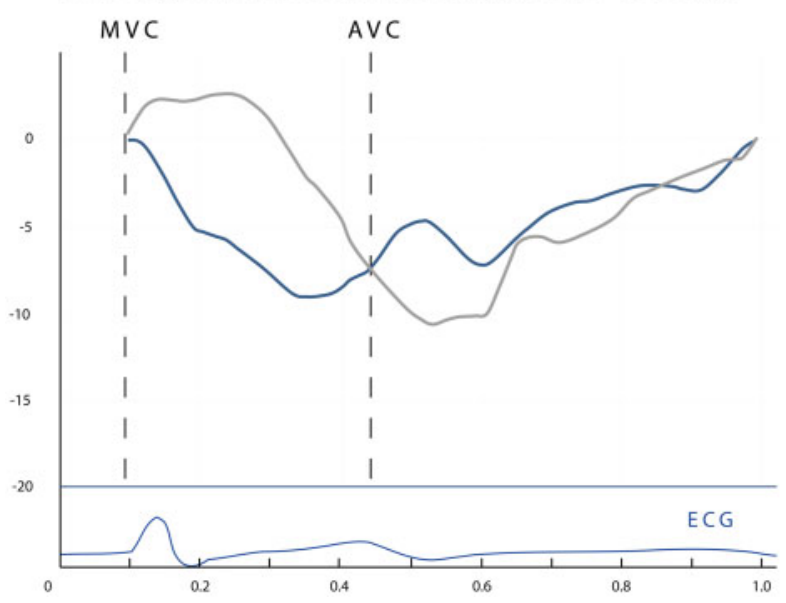

B Non-responder without apical rocking but high SRSsept

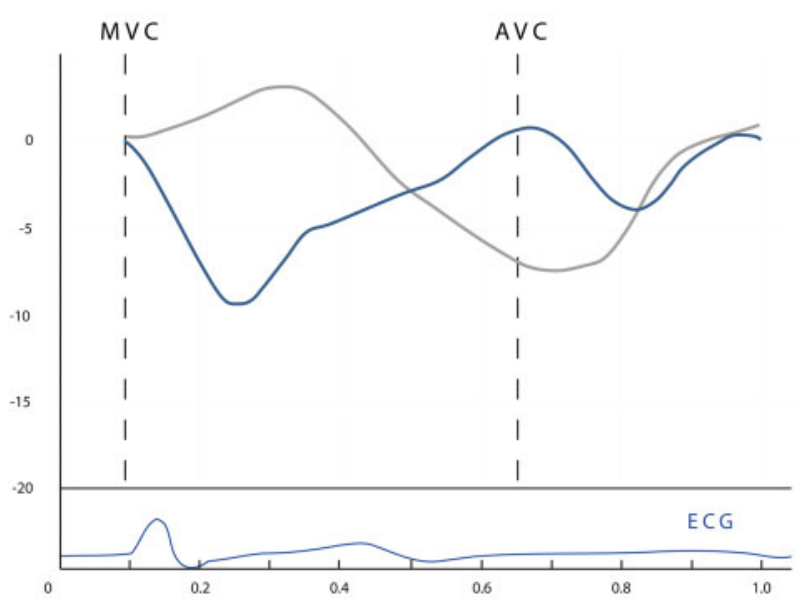

D Non-responder without apical rocking and low SRSsept

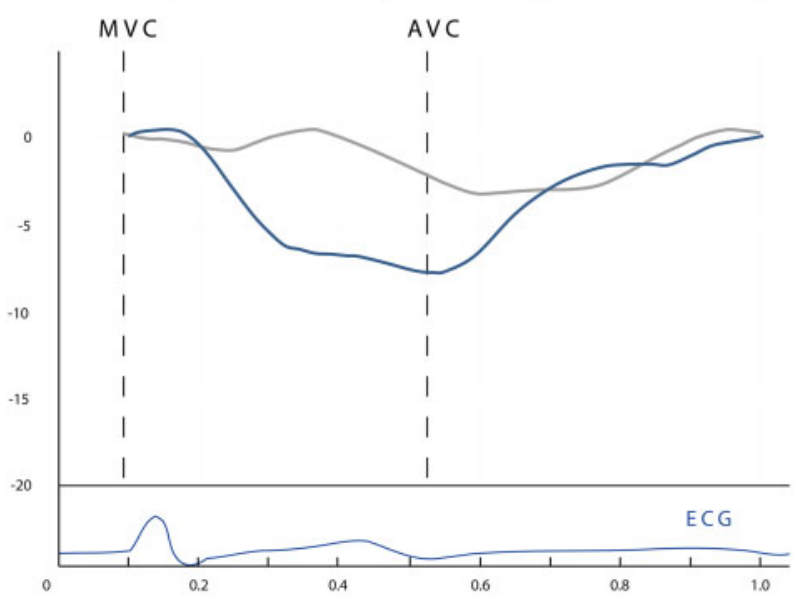

Figure 3 Strain based deformation patterns of patients with and without apical rocking. Strain curves (blue = septal, gray = lateral wall) of representative CRT recipients with and without apical rocking at baseline. (A) A 50-year-old woman with non-ICM, LVEF 30\%, LBBB, QRSd 186 ms, ApRock and high SRSsept (4.0\%) with a double peak pattern according to Leenders et al. ${ }^{17}$ LVESV change at 6 months of follow-up: -40.7\%. (B) A 78-year-old man with ICM, LVEF 15\%, non-LBBB, QRSd 187 ms, no ApRock but SRSsept values (10\%). At follow-up LVESV change was -1\%. (C) A 62-year-old man with ICM, LVEF 28\%, non-LBBB, and a QRSd of $189 \mathrm{~ms}$. Echocardiography relieved ApRock, but low SRSsept (1.6\%) and LVESV change at follow-up was -3\%. (D) A 69-year-old man with ICM, LVEF 12\%, LBBB, QRSd 188 ms, no ApRock and low SRSsept (0\%). LVESV change at follow-up was +1\%. ApRock, apical rocking; ICM, ischaemic cardiomyopathy; LBBB, left bundle branch block; LVEF, left ventricular ejection fraction; LVESV, LV end-systolic volume.

Consequently, assessment of mechanical dyssynchrony has additive predictive value, and may especially be useful to select patients without a strict LBBB but with an underlying substrate responsive to CRT.

\section{Strain parameters for prediction of CRT response}

Myocardial deformation analysis by speckle tracking echocardiography has become an established echocardiographic modality for assessing the mechanical consequences of dyssynchonous hearts failure. Dyssynchronous electrical activation affects LV pump function in a negative way due to opposing shortening and stretching within the left ventricle. ${ }^{16}$ Systolic stretching of the myocardium does not contribute to LV ejection and, therefore, represents a waste of energy (wasted work). ${ }^{24}$ Previous work suggested that the septum is particularly subject to wasted work caused by an LV activation delay and that the amount of septal wasted work is strongly correlated to CRT response. ${ }^{25}$ In 21 CRT patients, Vecera et al. ${ }^{25}$ displayed an average of $100 \%$ wasted work in the septum, whereas wasted work in the LV free wall was approximately $20 \%$, meaning that in their study population the septum essentially made no contribution to LV ejection. Although myocardial wasted work can be elegantly determined by the combination of speckle tracking-derived strain with LV pressure in LV pressure-strain loop analysis, specialized software is currently needed for its assessment. ${ }^{24}$ Strain analyses with speckle tracking echocardiography, on the other hand, is more readily 


\section{LBBB}

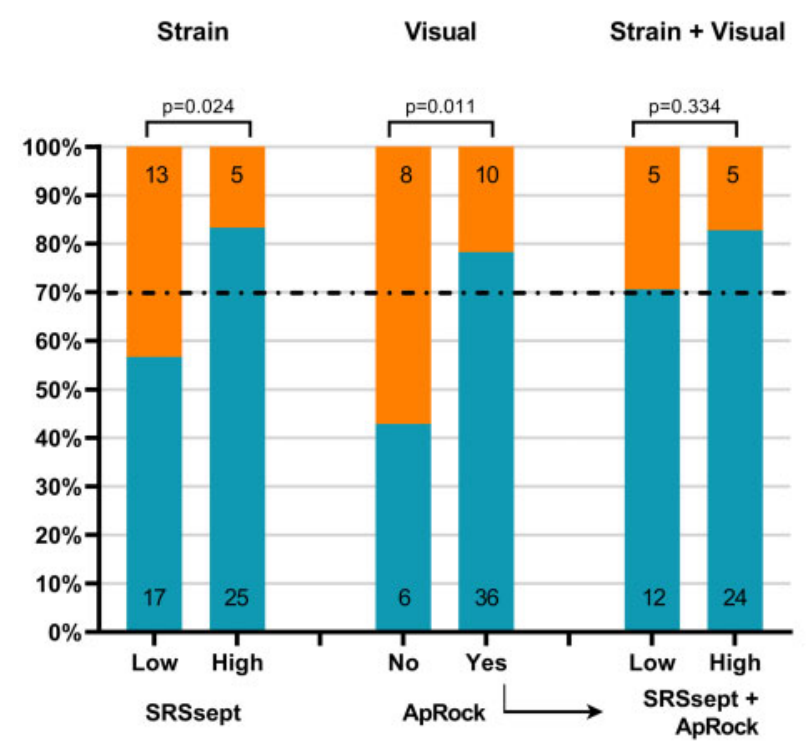

\section{non-LBBB}

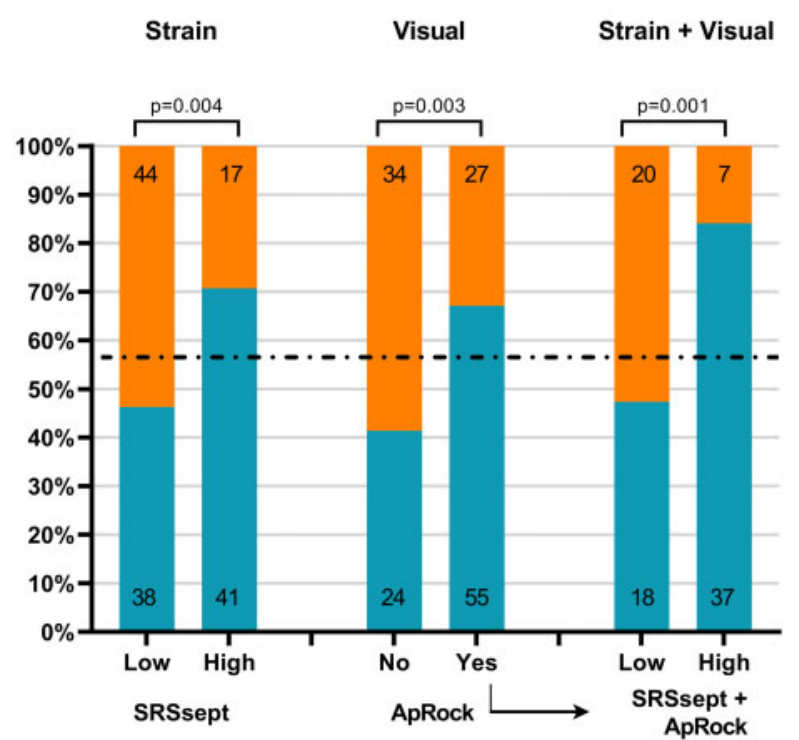

Figure 4 Discriminative ability of mechanical dyssynchrony in patients with and without a strict LBBB. The percentage of responders (blue) and non-responders (orange) are displayed for patients with high vs. low SRSsept (left), patients with and without apical rocking (middle), and patients with apical rocking and high or low SRSsept (right). Dotted line represents overall response to CRT in the subgroups. Numbers represent total amount of patients. ApRock, apical rocking; LBBB, left bundle branch block; SRSsept, systolic rebound stretch of the septum.

available because it is already implemented into echocardiography machines. A few clinical studies and work from computer modelling suggested that the amount of systolic stretching, by itself, may serve as marker for CRT response. ${ }^{5,8,17,26}$ A recent subanalysis of the multicentre Adaptive-CRT study displayed that the total amount of LV stretching [the systolic stretch index (SSI) which combines SRSsept with the prestretch of the LV lateral wall] was associated with better survival after CRT. ${ }^{8}$ This was not only true for the whole cohort but interestingly also for patients with intermediate ECG criteria (QRS 120-149 ms or non-LBBB) [hazard ratio (HR) high SSI: 5.08, 95\% confidence interval (Cl) 1.94-13.31, $P<0,001]$. In the present study, we choose to evaluate SRSsept instead of SSI because de Boeck et al. ${ }^{5}$ displayed that SRSsept is markedly more reduced by CRT than the systolic prestretch of the lateral wall. In addition, acquiring highquality images of the septum is easier as compared to high-quality image acquisition of the LV lateral wall. The association between SRSsept and CRT response has been evaluated previously by multiple single-centre studies that displayed SRSsept to be independently associated with long-term prognosis and improvements in LV remodelling. 5,6,20,21 This may, for an important part, be attributed to the fact that SRSsept is not only affected by the underlying electrical substrate (increasing SRSsept) but is also influenced by myocardial stiffness and scarring (generally reducing SRSsept), given that early septal shortening happens in viable, early activated septal segments and rebound stretch is affected by the contractility of the late activated lateral wall. 5,20 Of particular interest is that septal hypocontractility increases rebound stretch and leads to a predominant stretching pattern of the septum described by Leenders et al. ${ }^{17,27}$ and displayed in our Figure 3B. This might explain why in the present study some patients, despite high SRSsept values, demonstrated non-response to CRT. Lateral hypocontractility or scar, on the other hand, reduces rebound stretch and creates a pseudonormal septal strain pattern according to Leenders et al. ${ }^{17,27}$ (Figure 3C and D), which is associated with an overall poor response to CRT.

Finally, previous work displayed that not only the amount of mechanical dyssynchrony at baseline but also its correction by CRT are associated to greater reductions in LVESV. ${ }^{13}$ Moreover, a recent study displayed that not only do CRT-recipients with mechanical dyssynchrony have better survival over those without mechanical dyssynchrony, but also, that these patients have better long-term outcomes compared to patients with mechanical dyssynchrony who do not receive CRT. ${ }^{28}$ These findings further fuel the notion that mechanical dyssynchrony parameters can be used to assess a patients underlying substrate which can be corrected by CRT. Still, in the present study, the greater $\triangle$ LVESV in patients with larger reductions of SRSsept at follow-up seem to be driven in part by the amount of baseline mechanical dyssynchrony, since larger reductions in SRSsept did not result in significantly more reverse remodelling in the individual subgroups of patients with baseline low or high SRSsept.

\section{Visual detection of dyssynchrony vs. quantitative strain analysis}

A known limitation of speckle tracking strain analysis is that technically adequate echocardiographic image quality is required. ApRock, on the other hand, can be easily visually assessed on conventional 2D echocardiographic images, surpassing the need for expensive 
software and sophisticated strain analysis. Several studies, both single and multicentre, displayed that ApRock is associated with superior outcomes and more reverse remodelling after CRT and has added value over patient selection based solely on the 12 -lead ECG. ${ }^{12-15}$ In a subanalysis of the PREDICT-CRT database, presence of ApRock and/or septal flash at baseline was associated with lower all-cause mortality in both patients with an LBBB and non-LBBB morphology ( $\mathrm{HR} 0.21,95 \% \mathrm{Cl} 0.15-0.30, P<0.0001$ in LBBB, HR 0.47, 95\% Cl $0.27-0.82, P=0.007$ in non-LBBB QRS $\geq 150 \mathrm{~ms}$, and HR 0.35, 95\% Cl $0.14-0.87, P=0.02$ in non-LBBB QRS $<150 \mathrm{~ms}) .^{15}$ Interestingly, this study also revealed that adding mechanical dyssynchrony as selection criterion coincided with a significantly more volumetric responders compared to patient selection based on QRS duration and morphology alone $(77 \%$ vs. $65 \%$ in LBBB patients, $75 \%$ vs. $50 \%$ in non-LBBB QRS $\geq 150 \mathrm{~ms}$, and $62 \%$ vs. $38 \%$ in non-LBBB QRS $<150$ $\mathrm{ms}$, respectively). ${ }^{15}$ Although the PREDICT study did not report on the definition used to determine LBBB on the ECG, we believe that our results are in line with the aforementioned findings. Still, when using ApRock or septal flash to determine the presence of dyssynchrony, a continuous mechanical process is translated to an binary yes/no phenomenon. In the present study, approximately a quarter of patients with strict LBBB did not demonstrate ApRock. In these patients, CRT response was limited (43\%), and evaluation of SRSsept did not lead to a better response discrimination, suggesting that the absence of ApRock may be an important marker for predicting CRT non-response. Yet, 37\% of patients with LBBB and ApRock had low SRSsept values. These patients were significantly less often CRT responder. Previous work suggested that other nonelectrical factors (e.g. scar) may mimic visual dyssynchrony (e.g. ApRock or septal flash), which are unresponsive to CRT. ${ }^{27}$ This could explain why in the present study assessment of SRSsept held additional predictive power over the more simple assessment of ApRock.

\section{Clinical implications}

In the present study, presence of mechanical dyssynchrony markedly improved CRT response rates. This was not only true for patients with intermedicate ECG criteria (non-LBBB) but even for patients with a strict $L B B B$, in whom overall response to CRT is already fairly high. These present results should encourage cardiologists to look further than QRS morphology to determine a patient's eligibility for CRT. The assessment of SRSsept may be of special interest in patient showing ApRock, because non-electrical factors might lead to ApRock which are unresponsive to CRT. Finally, in the current study, the association between SRSsept and volumetric response to CRT was strongest for SRSsept derived from the focused septal single wall image, suggesting that high-quality focused images of the septum may especially be suited for improvement of echocardiography-based patient selection.

\section{Limitations}

Although the MARC study was a prospective multicentre study, the non-randomized and observational study design precludes a formal analysis of the interaction between baseline predictors and the prognostic benefit rendered by CRT. In addition, only patients with an LBBB or wide IVCD ( $\geq 150 \mathrm{~ms}$ ) were included in the MARC study. Application of mechanical dyssynchrony in patients with right bundle branch block or those with ICVD 130-149 ms may, therefore, be of interest for future research. Also, a known limitation of speckle tracking is that it cannot be applied to all patients. Yet in our study of six centres, only in 7 out of 213 patients (3\%) SRSsept assessment was not feasible, which is low compared to previously published work. ${ }^{6,8}$ Acquiring high-quality images of the septum is easier as compared to high-quality image acquisition of the LV lateral wall. As a consequence, we believe that SRSsept is a robust and relatively easy to use predictor of CRT response. Importantly, besides being dependent on image quality, SRSsept is also dependent on the specific image chosen (i.e. focused septal single wall vs. four-chamber view), the echocardiographic image system and speckle tracking vendor used. ${ }^{29}$ The cut-off value of $2.4 \%$ can therefore not be extrapolated to other vendors. Accordingly, specific cut-off values for SRSsept should be investigated in prospective trials in order to make an impact on CRT patient selection.

\section{Conclusion}

Our findings indicate that current electrocardiographic guideline criteria for CRT leave a substantial place for improvement in patient selection by incorporating echocardiographic assessment of the mechanical consequences of electrical LV dyssynchrony. Moreover, measuring 'septal rebound stretch' by speckle tracking strain analysis provides additional prognostic information on top of visual detection of mechanical dysysnchrony (i.e. apical rocking) for prediction of volumetric CRT response. Especially in patients with non-strict LBBB in whom benefit of CRT is doubted, septal rebound stretch is a promising marker of benefit from CRT and should be considered for validation in prospective clinical trials.

\section{Supplementary data}

Supplementary data are available at European Heart Journal - Cardiovascular Imaging online.

\section{Funding}

This research was performed within the framework of CTMM, the Centre for Translational Molecular Medicine (www.ctmm.nl), project COHFAR (01C-203), and supported by the Dutch Heart Foundation.

Conflict of interest: A.H.M.: lecture fees from Medtronic and LivaNova. B.G.: Salary and shares of Medtronic. F.W.P.: research grants from Medtronic, St Jude Medical, Biotronik, Sorin, Biosense Webster, EBR Systems and is a member on the Medtronic Advisory Board. K.V.: consultancy for Medtronic; Medtronic research grants, speaker fees from St. Jude Medical. M.A.V.: funding from CTMMCOHFAR, CVON Predict, EU TrigTreat, EU CERT_ICD, and GiLead to perform (pre)clinical studies.

\section{References}

1. Brignole M, Auricchio A, Baron-Esquivias G, Bordachar P, Boriani G, A Breithardt $O$ et al. 2013 ESC Guidelines on cardiac pacing and cardiac resynchronization therapy. Eur Heart J 2013;34:2281-329.

2. Tracy CM, Epstein AE, Darbar D, DiMarco JP, Dunbar SB, Estes NAM et al. 2012 ACCF/AHA/HRS focused update incorporated into the ACCF/AHA/HRS 2008 guidelines for device-based therapy of cardiac rhythm abnormalities. J Am Coll Cardiol 2013; 61:e6-75. 
3. Auricchio A, Prinzen FW. Non-responders to cardiac resynchronization therapy — the magnitude of the problem and the issues. Circ J 2011;75:521-7.

4. Chung ES, Leon AR, Tavazzi L, Sun JP, Nihoyannopoulos P, Merlino J et al. Results of the predictors of response to CRT (PROSPECT) trial. Circulation 2008; 117:2608-16.

5. De Boeck BWL, Teske AJ, Meine M, Leenders GE, Cramer MJ, Prinzen FW et al. Septal rebound stretch reflects the functional substrate to cardiac resynchronization therapy and predicts volumetric and neurohormonal response. Eur J Heart Fail 2009;11:863-71.

6. Lumens J, Tayal B, Walmsley J, Delgado-Montero A, Huntjens PR, Schwartzman $\mathrm{D}$ et al. Differentiating electromechanical from non-electrical substrates of mechanical discoordination to identify responders to cardiac resynchronization therapy. Circ Cardiovasc Imaging 2015;8:e003744.

7. Risum N, Tayal B, Hansen TF, Bruun NE, Jensen MT, Lauridsen TK et al. Identification of typical left bundle branch block contraction by strain echocardiography is additive to electrocardiography in prediction of long-term outcome after cardiac resynchronization therapy. J Am Coll Cardiol 2015;66:631-41.

8. Gorcsan J, Anderson CP, Tayal B, Sugahara M, Walmsley J, Starling RC et al. Systolic stretch characterizes the electromechanical substrate responsive to cardiac resynchronization therapy. JACC Cardiovasc Imaging 2019;12:1741-52

9. Szulik M, Tillekaerts M, Vangeel V, Ganame J, Willems R, Lenarczyk R et al. Assessment of apical rocking: a new, integrative approach for selection of candidates for cardiac resynchronization therapy. Eur J Echocardiogr 2010;11:863-9.

10. Mada RO, Lysyansky P, Duchenne J, Beyer R, Mada C, Muresan L et al. New automatic tools to identify responders to cardiac resynchronization therapy. J Am Soc Echocardiogr 2016;29:966-72.

11. van Everdingen W, Schipper JC van 't Sant J, Ramdat Misier K, Meine M, Cramer M. Echocardiography and cardiac resynchronisation therapy, friends or foes? Neth Heart J 2016;24:25-38.

12. Ghani A, Delnoy PPH, Ottervanger JP, Misier ARR, Smit JJJ, Adiyaman A et al. Apical rocking is predictive of response to cardiac resynchronization therapy. Int J Cardiovasc Imaging 2015;31:717-25.

13. Stankovic I, Prinz C, Ciarka A, Daraban AM, Kotrc M, Aarones M et al. Relationship of visually assessed apical rocking and septal flash to response and long-term survival following cardiac resynchronization therapy (PREDICT-CRT). Eur Heart J Cardiovasc Imaging 2016;17:262-9.

14. Maass AH, Vernooy K, Wijers SC, van 'T Sant J, Cramer MJ, Meine $M$ et al. Refining success of cardiac resynchronization therapy using a simple score predicting the amount of reverse ventricular remodelling: results from the Markers and Response to CRT (MARC) study. Europace 2018;20:e1-10.

15. Beela AS, Serkan U, Ciarka A, Daraban AM, Kotrc M, Aarones M et al. Assessment of mechanical dyssynchrony can improve the prognostic value of guideline-based patient selection for cardiac resynchronization therapy. Eur Heart J Cardiovasc Imaging 2019;20:66-74.

16. Prinzen FW, Hunter WC, Wyman BT, Mcveigh ER. Mapping of regional myocardial strain and work during ventricular pacing: experimental study using magnetic resonance imaging tagging. J Am Coll Cardiol 1999;33:1735-42.
17. Leenders GE, Lumens J, Cramer MJ, De Boeck BWL, Doevendans PA, Delhaas T et al. Septal deformation patterns delineate mechanical dyssynchrony and regional differences in contractility analysis of patient data using a computer model. Circ Heart Fail 2012;5:87-96.

18. Galli E, Leclercq C, Fournet M, Hubert A, Bernard A, Smiseth OA et al. Value of myocardial work estimation in the prediction of response to cardiac resynchronization therapy. J Am Soc Echocardiogr 2018;31:220-30.

19. Smiseth OA, Russell K, Skulstad H. The role of echocardiography in quantification of left ventricular dyssynchrony: state of the art and future directions Otto. Eur Heart J Cardiovasc Imaging 2012;13:61-8.

20. Leenders GE, De Boeck BWL, Teske AJ, Meine M, Bogaard MD, Prinzen FW et al. Septal rebound stretch is a strong predictor of outcome after cardiac resynchronization therapy. J Card Fail 2012;18:404-12.

21. Van Sant J, Horst IAH, Wijers SC, Mast TP, Leenders GE, Doevendans PA et al. Measurements of electrical and mechanical dyssynchrony are both essential to improve prediction of CRT response. J Electrocardiol 2015;48:601-8.

22. Voigt J, Schneider T, Korder S, Szulik M, Daniel WG, Rademakers F et al. Apical transverse motion as surrogate parameter to determine regional left ventricular function inhomogeneities: a new, integrative approach to left ventricular asynchrony assessment. Eur Heart J 2008;30:959-68.

23. Surawicz B, Childers R, Deal BJ, Gettes LS. AHA/ACCF/HRS Recommendations for the Standardization and Interpretation of the Electrocardiogram. J Am Coll Cardiol 2009;53:976-81.

24. Russell K, Eriksen M, Aaberge L, Wilhelmsen N, Skulstad H, Gjesdal O Assessment of wasted myocardial work: a novel method to quantify energy loss due to uncoordinated left ventricular contractions. Am J Physiol Heart Circ Physiol 2013;305:996-1003.

25. Vecera J, Penicka M, Eriksen M, Russell K, Bartunek J, Vanderheyden M et al. Wasted septal work in left ventricular dyssynchrony: a novel principle to predict response to cardiac resynchronization therapy. Eur Heart J Cardiovasc Imaging 2016;17:624-32.

26. Lumens J, Tayal B, Walmsley J, Delgado-Montero A, Huntjens PR, Schwartzman $\mathrm{D}$ et al. Differentiating electromechanical from non-electrical substrates of mechanical discoordination to identify responders to cardiac resynchronization therapy. Circ Cardiovasc Imaging 2015;8:e003744.

27. Aalen JM, Remme EW, Larsen CK, Andersen OS, Krogh M, Duchenne J et al Mechanism of abnormal septal motion in left bundle branch block: role of left ventricular wall interactions and myocardial scar. JACC Cardiovasc Imaging 2019;12: 2402-13.

28. Stankovic I, Stefanovic M, Prinz C, Ciarka A, Daraban AM, Kotrc M et al. The association of mechanical dyssynchrony and resynchronization therapy with survival in heart failure with a wide QRS complex: a two-world study. Int J Cardiovasc Imaging 2020;doi:10.1007/s10554-020-01865-x.(Eprint ahead of publication)

29. Van Everdingen WM, Maass AH, Vernooy K, Meine M, Allaart CP, De Lange FJ et al. Comparison of strain parameters in dyssynchronous heart failure between speckle tracking echocardiography vendor systems. Cardiovasc Ultrasound 2017;15:25. 